BULLETIN OF ENVIRONMENTAL SCIENCE \&
SUSTANNABLE MANAGEMENT
WUBLISHER

\title{
Optimization of Process Conditions for Effective Degradation of Azo Blue Dye by Streptomyces sp. DJP15: A Secondary Modelling Approach
}

\author{
Garba Uba ${ }^{1 *}$ Abdussamad Abubakar ${ }^{2}$ and Salihu Ibrahim ${ }^{3}$ \\ ${ }^{1}$ Department of Science Laboratory Technology, College of Science and Technology, Jigawa State Polytechnic, Dutse, \\ PMB 7040, Nigeria. \\ ${ }^{2}$ Department of Microbiology, Faculty of Science, Gombe State University. \\ ${ }^{3}$ Center for Biotechnology studies, Department of Biochemistry, College of Basic Medical Science, \\ Bayero University, Kano.
}

*Corresponding author: Garba Uba, Department of Science Laboratory Technology,

College of Science and Technology, Jigawa State Polytechnic,

Dutse,

PMB 7040,

Nigeria.

Email: garbauba@jigpoly.edu.ng

\section{HISTORY \\ Received: 23 ${ }^{\text {rd }}$ Aug 2021 Received in revised form: $25^{\text {th }}$ Oct 2021 Accepted: $19^{\text {th }}$ Nov 2021}

\section{KEYWORDS}

Azo blue dye

Biodegradation

Streptomyces

Substrate inhibition mode

Monod

\begin{abstract}
The well function of aquatic and soil organisms including terrestrial, as well as those of all other living things, can be jeopardized if dyes aren't properly treated, as their degradation might lead to carcinogenic chemicals. Complete mineralization of dye is the only option, and this can be done using microorganisms. The azo blue dye inhibitory effect to its biodegradation by Streptomyces DJP15 was modelled using several inhibition kinetic models such as Haldane, Monod, Luong, Aiba, Teissier-Edwards, Han-Levenspiel and Yano. The result shows that only the Luong model failed to fit the data. The rest of the models visually $\mathrm{ft}$ the data although data fitting is problematic with datapoints of less than 10, which the result in this work demonstrates where it is not easy to choose the best model where nearly all of the models fit the data in a similar manner. Resorting to statistical discriminatory function, the best model was Monod with the smallest RMSE and AICc values and the highest adj $\mathrm{R}^{2}$ values and values for $\mathrm{AF}$ and $\mathrm{BF}$ close to unity. However, Monod has only two parameters and is the most robust. The Monod's parameters were maximum specific degradation rate of $0.431(1 / \mathrm{h})(95 \%$ confidence interval from 0.391 to $0.456)$ and concentration of substrate giving half maximal rate or $K_{s}$ value of $0.0001(\mathrm{mg} / \mathrm{L})(95 \%$ C.I. from -0.01 to 12.12 ). The confidence interval value for the $K_{s}$ value was very large indicating poor data quality. This should be an important consideration in future works where the data point number can be increased to improve model fitting exercise.
\end{abstract}

\section{INTRODUCTION}

Azo dyes are the most common and versatile synthetic dyes used in the textile industry, accounting for more than half of all synthetic dyes manufactured each year [1]. Depending on the number of azo groups, azo dyes are classed as diazo dyes (brown 2 , reactive brown 1 , acid black 1 , amido black), mono azo dyes (reactive yellow 201, acid orange 52, disperse blue 399), poly azo dyes (direct red 80) and tris azo dyes (direct black 19 and direct blue 78,) [2]. Azo dyes are characterized as reactive, dispersion, direct, cationic, anionic, and metalized azo dyes 1 based on their application [3]. They're the only azo dyes that can bind covalently to cellulosic fibre and are widely used in the textile industry." They are very water-soluble and non-degradable in the normal aerobic conditions seen in biological treatment systems because of their strong sulphonation [4]. There are several - $\mathrm{SO}_{3} \mathrm{H}$ - group dyes in industrial effluents that are sulfonated azo dyes. Antidegradation properties are seen in the vast majority of azo dyes. Chemically, the dyes are poisonous and inert due to the presence of sulfo and azo groups, which aren't found in nature [5].

Without proper treatment, dyes can stay in the environment for long periods of time, posing a threat not only to aquatic plants' photosynthetic processes, but also to all living organisms, as their breakdown can result in carcinogenic compounds [6]. Allergenic, carcinogenic, mutagenic, and teratogenic in humans, these compounds bioaccumulate in the environment. When dyes are released into the water, they reduce the concentration of dissolved oxygen, which leads to the death and putrefaction of aquatic organisms. In recent years, bioremediation has been recognised as a successful, specific, less energy-intensive, and ecologically friendly technology since it results in stable, 
harmless end products by partially or completely bioconverting pollutants. The goal of microbial bioremediation is to increase the natural degrading capacity of microorganisms [7].

The use of microorganisms in biodegradation is growing in popularity since it is a low-cost, ecologically friendly technology that generates less sludge and yields non-toxic finished products. Azo dyes may be decolored by a variety of microorganisms, including bacteria, fungi, actinomycetes, and algae. Microorganism decolorization activity is strongly influenced by environmental circumstances. As $\mathrm{pH}$ and temperature increase, the stability of the enzyme system that degrades dyes may be altered, resulting in diminished decolorization activity, which may have an impact on the strain's survival. Different environmental factors, such as carbon supply, nitrogen source, dye concentration, aeration and temperature as well as $\mathrm{pH}$ and the incubation duration affect the bacteria's ability to decolorize [8-17]. Dye biodegradation by microorganisms is subjected to the toxicity of the dye or the dye metabolite itself which require the inhibitory effects to be analyzed using mathematical models such as Haldane, Aiba and Luong [18-21].

Comparing and contrasting the models based on openly available data is the purpose of this study, which aims to undertake more thorough modelling and answer which models may be used based on statistical reasoning. As a result of these new findings, researchers will be able to explore new information and enhance their prior findings. The goal of this study is to improve the process parameters for successful degradation of Azo blue using a secondary modelling technique by streptomyces DJP15.

\section{MATERIALS AND METHODS}

\section{Acquisition of Data}

Web Plot Digitizer 2.5[22] was used to digitise scanned plots into tables of data with sufficient precision before the data could be handled electronically. A previously published data [3], from Figures 2 which shows the degradation of Azo blue by streptomyces DJP15 at different concentrations were used in this study.

\section{Fitting of the data}

Curve Expert Professional software was used to fit the nonlinear models to the azo dye degradation data using nonlinear regression and a Marquarsdt approach that minimizes the sums of squares of the difference between observed and fitted data, which is the residuals (Version 1.6). Calculation of initial values is automated by looking for the sharpest rise in the curve four four data points (estimation of $m_{\max }$ ), and the cross of the line with the x-axis (which estimates the lag period or lambda), and by exploitation the final data point as an assessment to determine the maximum or asymptote $(A)$.

\section{Statistical analysis}

An experiment was used to compare the quality of models with various numbers of parameters, and data were analysed using numerous statistical approaches including adjusted coefficient of determination $\left(\operatorname{adj} R^{2}\right)$, the Root Mean Square Error (RMSE), bias factor (BF), accuracy factor (AF), and AICc, which is a corrected form of the original Akaike Information Criterion (AIC) to see if a statistically significant difference existed (Akaike Information Criterion) [23]. The RMSE was calculated according to Eq. (1), where predicted values are Pdi and obserbed values are Obi. The no of datapoints are $\mathrm{n}$ while the no of parameter is $p$. It is expected according to theory that the model with the smaller number of parameters will give a smaller RMSE value [24].

$R M S E=\frac{\sqrt{\sum_{i=1}^{N}(p d i-O b i)^{2}}}{n-p}$

Linear regression models employ the coefficient of determination, or R2, to evaluate the model's fit. Nonetheless, if the number of parameters differs between models in a nonlinear regression, the technique fails to provide comparable analyses. For nonlinear models, the R2 formula is adjusted to include RMS, which is the residual mean squared error and $\mathrm{S} 2 \mathrm{y}$ is the total variance of the Y-variable.

$\operatorname{Adjusted}\left(R^{2}\right)=1-\frac{R M S}{S^{2} y}$

Adjusted $\left(R^{2}\right)=1-\frac{\left(1-R^{2}\right)(n-1)}{n-p-1}$

If you want to know how well your statistical model fits the data, you may use the Akaike information criterion (AIC). The higher the AIC score, the less desired the outcome or the more parameters are incorporated in the computation. Overfitting is encouraged and discouraged by AIC, which favours the employment of a more complex model for fitting scientific results. Since the amount of data in this study is little in comparison to the number of parameters used, the Akaike information criterion (AIC) with correction (AICc) is used instead of the corrected version of AIC [25].

Table 1. Various mathematical models developed for growth kinetics involving substrate inhibition.

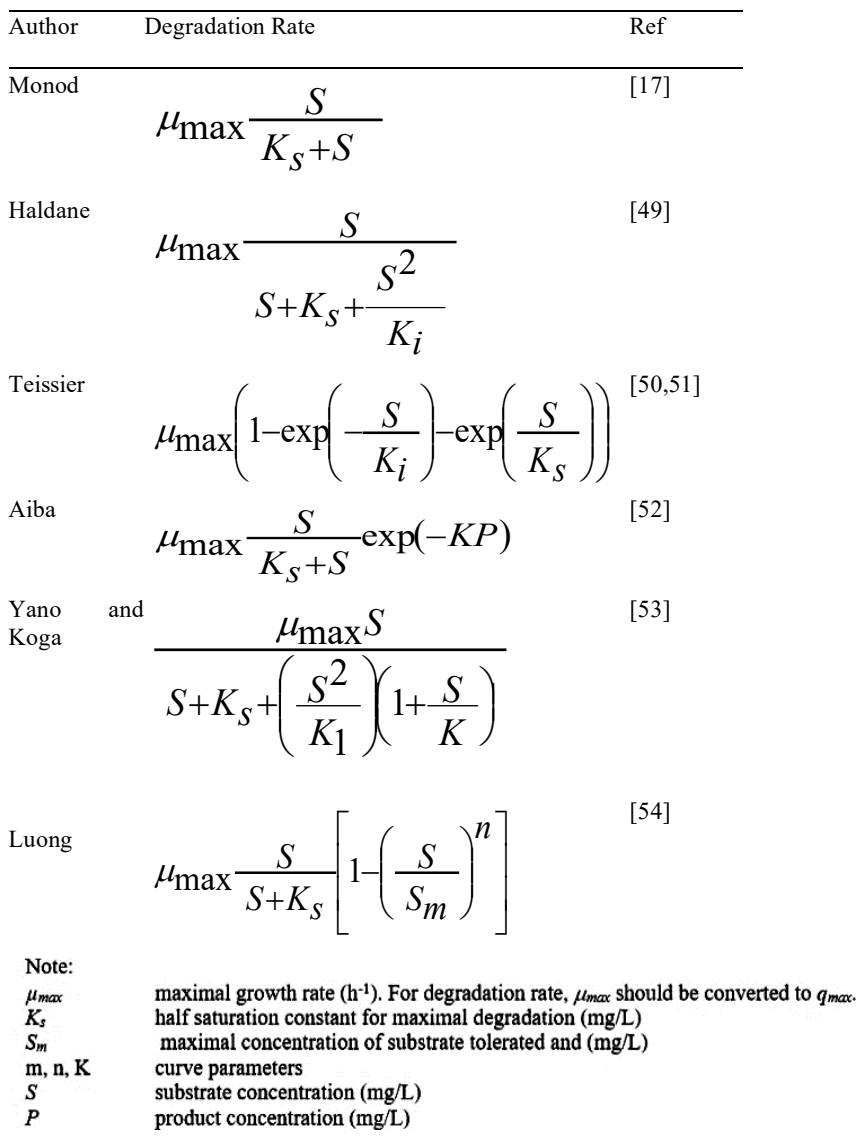


Table 2. Statistical analysis of kinetic models ( $\mathrm{p}$ is parameter).

\begin{tabular}{lllllll}
\hline Model & $\mathrm{p}$ & $\mathrm{RMSE}$ & $\mathrm{adR}^{2}$ & $\mathrm{AICc}$ & $\mathrm{BF}$ & $\mathrm{AF}$ \\
\hline Yano & 4 & 0.0311 & 0.954 & 23 & 1.001 & 1.035 \\
Tessier-Edward & 3 & 0.0895 & 0.689 & -4 & 0.988 & 1.135 \\
Aiba & 3 & 0.0270 & 0.970 & -21 & 1.001 & 1.035 \\
Haldane & 3 & 0.0270 & 0.970 & -21 & 1.001 & 1.035 \\
Monod & 2 & 0.0241 & 0.977 & -37 & 1.001 & 1.035
\end{tabular}

\section{RESULTS AND DISCUSSION}

Modified Gompertz, modified logistics, Huang, Buchanan-three phase, and Baranyi and Roberts models are one of the most used main models because they correctly simulate bacteria's development under [26-29].In spite of this, primary modelling is rarely utilised in the growth of bacteria on xenobiotics or in the enzymatic process of xenobiotic elimination. To better understand the impact of environmental factors on bacterial growth and metabolism, we do further model-based research. Microbes thriving on xenobiotics like phenol or catechol are inhibited by secondary models such as the Haldane, Aiba, and Yano. There are a large number of models that may be classed as either empirical or mechanistic, but the most majority of them lie somewhere in between. Growing bacteria or doing things with bacteria often has an identifiable phase where the rate of growth begins at zero and increases to a maximum value $(\max )$ over a set time period, leading to a time delay (lag) [30-34].

As a result of this last phase, in which the rate of change decreases until it reaches zero, growth curves are said to be asymptotical (A). Most of the time, differences in development rates lead to a sigmoidal curve with a lag period that begins immediately after $t=0$. The exponential step is distinguished by the presence of a static period, followed by a dying phase, and ultimately a rising phase. The maximum specific growth rate is an essential growth curve parameter that, together with the asymptotic value and the lag time, should not be disregarded while constructing a growth curve model $\left(m_{m}\right)$. This number is frequently utilised in the creation of secondary models, such as those examining the influence of substrate, $\mathrm{pH}$ product and temperature on an organism's growth rate. The result shows that only the Luong model failed to fit the data. The rest of the models visually $\mathrm{ft}$ the data although data fitting is problematic with datapoints of less than 10, which the result in this work demonstrates where it is not easy to choose the best model where nearly all of the models fit the data in a similar manner.

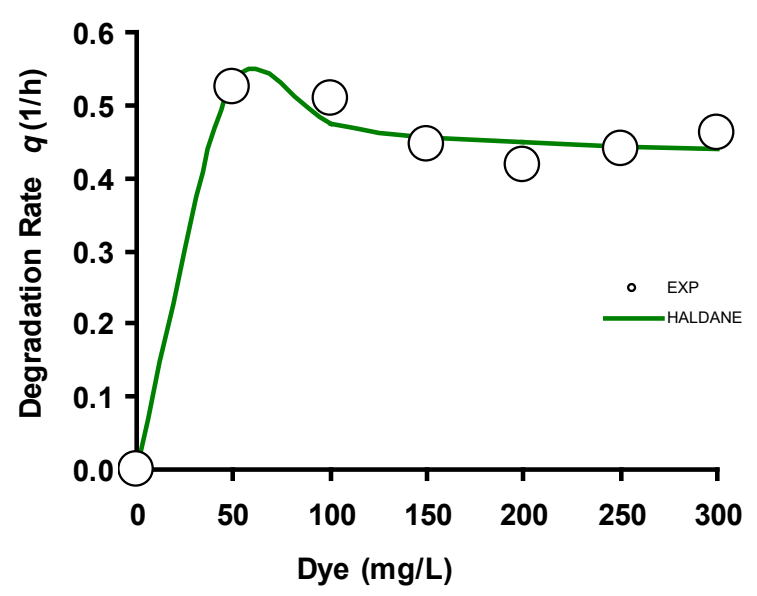

Fig. 1. Fitting experimental data with the Haldane model.

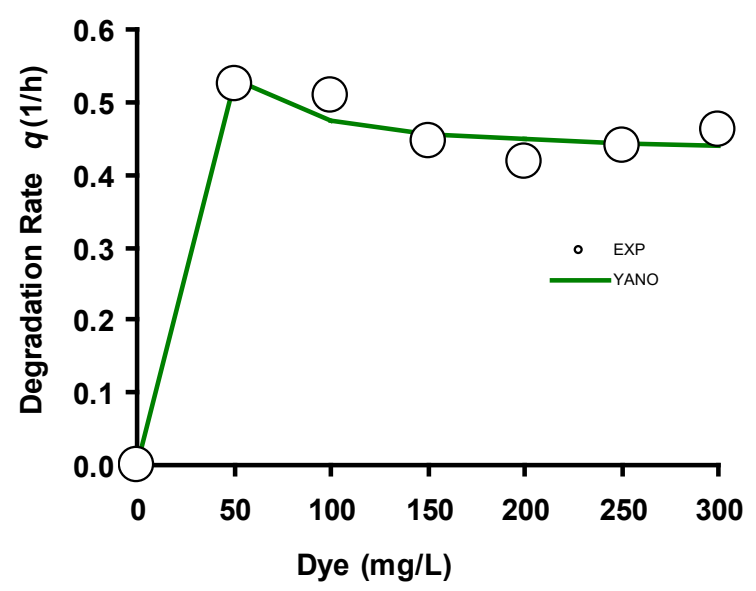

Fig. 2. Fitting experimental data with the Yano model.

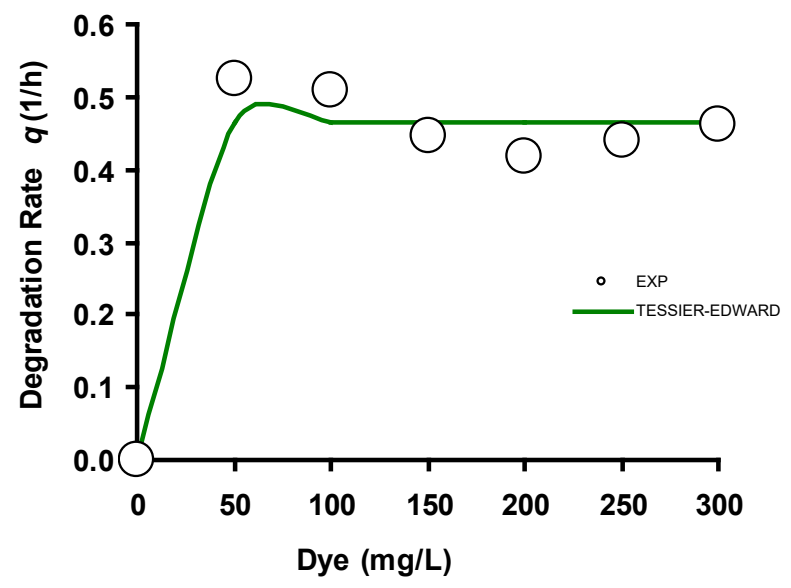

Fig. 3. Fitting experimental data with the Teissier model.

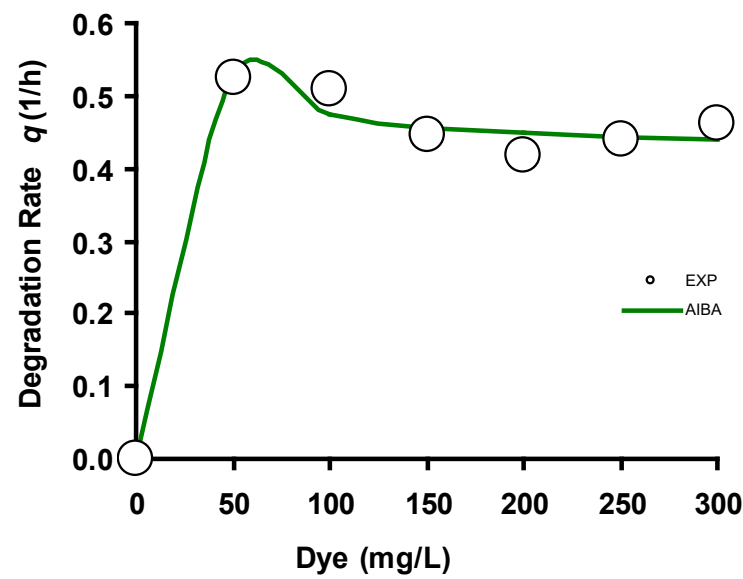

Fig. 4. Fitting experimental data with the Aiba model. 


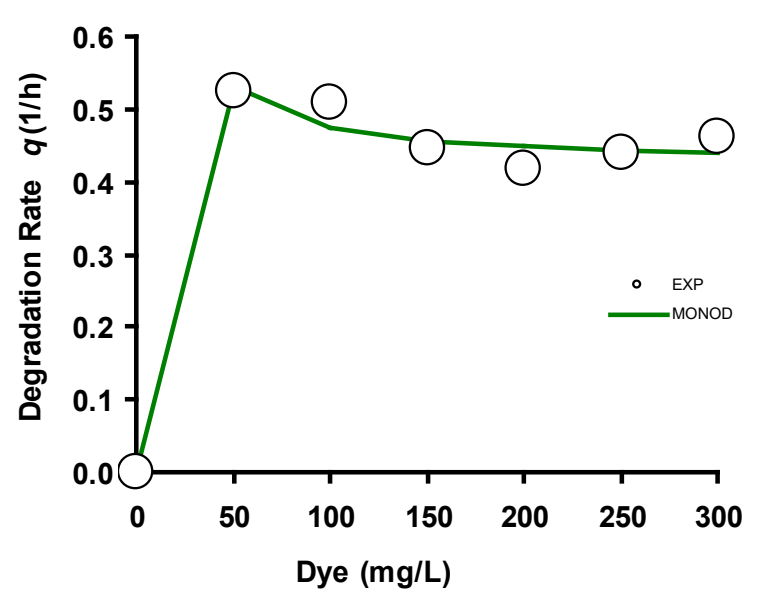

Fig. 5. Fitting experimental data with the Monod model.

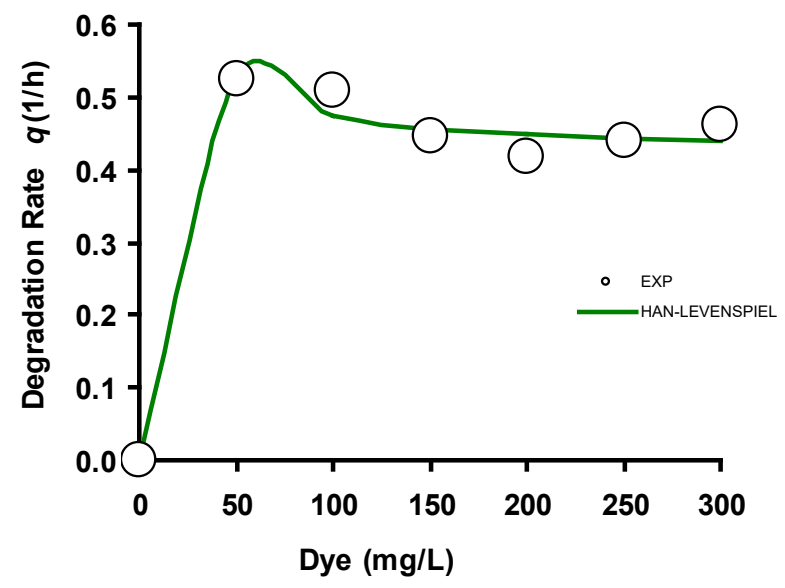

Fig. 6. Fitting experimental data with the Han-Levenspiel model.

The result shows that only the Luong model failed to fit the data. The rest of the models visually $\mathrm{ft}$ the data although data Resorting to statistical discriminatory function, the best model was Monod with the smallest RMSE and AICc values and the highest $a d j R^{2}$ values and values for $\mathrm{AF}$ and $\mathrm{BF}$ close to unity. However, Monod has only two parameters and is the most robust. The Monod's parameters were maximum specific degradation rate of $0.431(1 / \mathrm{h})(95 \%$ confidence interval from 0.391 to 0.456$)$ and concentration of substrate giving half maximal rate or $K_{s}$ value of $0.0001(\mathrm{mg} / \mathrm{L})(95 \%$ C.I. from -0.01 to 12.12$)$. The confidence interval value for the $K_{s}$ value was very large indicating poor data quality. This should be an important consideration in future works where the data point number can be increased to improve model fitting exercise.

The Monod model has found utility in modelling several microorganisms' related substrate inhibition kinetics. Despite the fact that many various growths rate equations have been presented in the literature, only a few are now in use in the real world. To characterise the development of microorganisms in general, and hydrogen-producing bacteria in particular, the empirical Monod equation is by far the most commonly used rate expression to quantify their growth [35]. Vogel et al., [36] describe Monod model as the best to fit the stimulation of growth by the concentration of nutrients in Saccharomyces cerevisiae on glucose and Escherichia on lactose. However, the Monod model is used to simulate algae growth in the photobioreactor since it is commonly used to model the growth of single celled organisms in a carbon-constrained environment [37]. Because most studies on the effects of toxic substrates on microbial growth use toxic substrates like aromatic and halogenated hydrocarbons, it's safe to infer that at high concentrations, growth rate will be significantly impeded, and other non-fitting models like Tessier will fail. The Monod model has been used to forecast a range of bacterial growths on xenobiotics and has been widely used as a general-purpose model for understanding substrate inhibition kinetics. The highest concentration at which cultures can sustain shock doses is known as the inhibition constant $(\mathrm{Ki})$. This is an extremely significant value. Literature search showed little mathematical modelling of the kinetics of dye degradation by microorganisms have been done with few examples exists [1821].

\section{CONCLUSION}

The dye inhibitory effect to its biodegradation by Streptomyces was modelled using several inhibition kinetic models. The result shows that only the Luong model failed to fit the data. The rest of the models visually $\mathrm{ft}$ the data although data fitting is problematic with datapoints of less than 10 , which the result in this work demonstrates where it is not easy to choose the best model where nearly all of the models fit the data in a similar manner. Resorting to statistical discriminatory function, the best model was Monod with the smallest RMSE and AICc values and the highest adj $\mathrm{R}^{2}$ values and values for $\mathrm{AF}$ and $\mathrm{BF}$ close to unity. However, Monod has only two parameters and is the most robust. The Monod's parameters were maximum specific degradation rate of $0.431(1 / \mathrm{h})(95 \%$ confidence interval from 0.391 to 0.456$)$ and concentration of substrate giving half maximal rate or $K_{s}$ value of $0.0001(\mathrm{mg} / \mathrm{L})(95 \%$ C.I. from -0.01 to 12.12$)$. The confidence interval value for the $K_{s}$ value was very large indicating poor data quality. This should be an important consideration in future works where the data point number can be increased to improve model fitting exercise.

\section{REFERENCES}

1. Slama HB, Chenari Bouket A, Pourhassan Z, Alenezi FN, Silini A, Cherif-Silini H, et al. Diversity of Synthetic Dyes from Textile Industries, Discharge Impacts and Treatment Methods. Appl Sci 2021 Jan;11(14):6255.

2. Adnan LA, Mohd Yusoff AR, Hadibarata T, Khudhair AB. Biodegradation of bis-azo dye reactive black 5 by white-rot fungus Trametes gibbosa sp. WRF 3 and its metabolite characterization. Water Air Soil Pollut. 2014;225(10).

3. Pillai HPJ. Optimization of Process Conditions for Effective Degradation of Azo Blue Dye by Streptomyces DJP15. J Pure Appl Microbiol. 2017 Dec 30;11:1757-65.

4. Lade H, Govindwar S, Paul D. Low-Cost Biodegradation and Detoxification of Textile Azo Dye C.I. Reactive Blue 172 by Providencia rettgeri Strain HSL1. J Chem [Internet]. 2015 [cited 2021 Sep 2];2015:1-10. Available from: http://www.hindawi.com/journals/jchem/2015/894109/

5. Rehorek A, Plum A. Characterization of sulfonated azo dyes and aromatic amines by pyrolysis gas chromatography/mass spectrometry. Anal Bioanal Chem. 2007 Aug;388(8):1653-62.

6. Lellis B, Fávaro-Polonio CZ, Pamphile JA, Polonio JC. Effects of textile dyes on health and the environment and bioremediation potential of living organisms. Biotechnol Res Innov [Internet]. 2019 Jul [cited 2021 Sep 2];3(2):275-90. Available from: https://linkinghub.elsevier.com/retrieve/pii/S2452072119300413

7. Ardila-Leal LD, Poutou-Piñales RA, Pedroza-Rodríguez AM, Quevedo-Hidalgo BE. A Brief History of Colour, the Environmental Impact of Synthetic Dyes and Removal by Using Laccases. Molecules. 2021 Jan;26(13):3813.

8. An S-Y, Min S-K, Cha I-H, Choi Y-L, Cho Y-S, Kim C-H, et al. Decolorization of triphenylmethane and azo dyes by Citrobacter $\mathrm{sp}$. Biotechnol Lett. 2002;24(12):1037-40.

9. Puvaneswari N, Muthukrishnan J, Gunasekaran P. Biodegradation of benzidine based azodyes Direct red and Direct blue by the 
immobilized cells of Pseudomonas fluorescens D41. Indian J Exp Biol. 2002;40(10):1131-6.

10. Adedayo O, Javadpour S, Taylor C, Anderson WA, Moo-Young M. Decolourization and detoxification of Methyl Red by aerobic bacteria from a wastewater treatment plant. World J Microbiol Biotechnol. 2004;20(6):545-50.

11. dos Santos AB, Cervantes FJ, van Lier JB. Azo dye reduction by thermophilic anaerobic granular sludge, and the impact of the redox mediator anthraquinone-2,6-disulfonate (AQDS) on the reductive biochemical transformation. Appl Microbiol Biotechnol. 2004 Mar;64(1):62-9.

12. Kolekar YM, Pawar SP, Gawai KR, Lokhande PD, Shouche YS, Kodam KM. Decolorization and degradation of Disperse Blue 79 and Acid Orange 10, by Bacillus fusiformis KMK5 isolated from the textile dye contaminated soil. Bioresour Technol. 2008;99(18):8999-9003.

13. Evangelista-Barreto NS, Albuquerque CD, Vieira RHSF, CamposTakaki GM. Cometabolic decolorization of the reactive azo dye orange II by Geobacillus stearothermophilus UCP 986. Text Res J. 2009;79(14):1266-73.

14. Bibi R, Arshad M, Asghar HN. Optimization of factors for accelerated biodegradation of reactive black-5 azo dye. Int J Agric Biol. 2012;14(3):353-9.

15. Tan L, Li H, Ning S, Hao J. Aerobic decolorization and degradation of Acid Orange G (AOG) by suspended growing cells and immobilized cells of a yeast strain Candida tropicalis TL-FL. Appl Biochem Biotechnol. 2014;174(4):1651-67.

16. Ayed L, Bakir K, Ben Mansour H, Hammami S, Cheref A, Bakhrouf A. In vitro mutagenicity, NMR metabolite characterization of azo and triphenylmethanes dyes by adherents bacteria and the role of the "cna" adhesion gene in activated sludge. Microb Pathog. 2017;103:29-39.

17. Goud BS, Cha HL, Koyyada G, Kim JH. Augmented Biodegradation of Textile Azo Dye Effluents by Plant Endophytes: A Sustainable, Eco-Friendly Alternative. Curr Microbiol. 2020;77(11):3240-55.

18. Inan Beydilli M, Pavlostathis SG. Decolorization kinetics of the azo dye Reactive Red 2 under methanogenic conditions: effect of longterm culture acclimation. Biodegradation. 2005 Mar 1;16(2):13546.

19. Gnanapragasam G, Senthilkumar M, Arutchelvan V, Velayutham $\mathrm{T}$, Nagarajan S. Bio-kinetic analysis on treatment of textile dye wastewater using anaerobic batch reactor. Bioresour Technol. 2011;102(2):627-32.

20. Srinivasan R, Kathiravan MN, Gopinath KP. Degradation of Tectilon Yellow $2 \mathrm{G}$ by hybrid technique: Combination of sonolysis and biodegradation using mutant Pseudomonas putida. Bioresour Technol. 2011;102(3):2242-7.

21. Yu L, Zhang X, Tang Q, Li J, Xie T, Liu C, et al. Decolorization characteristics of a newly isolated salt-tolerant Bacillus sp. strain and its application for azo dye-containing wastewater in immobilized form. Appl Microbiol Biotechnol. 2015 Nov 1;99(21):9277-87.

22. Rohatgi A. WebPlotDigitizer-Extract Data from Plots, Images, and Maps [Internet]. 2018 [cited 2019 Jan 1]. Available from: http://arohatgi. info/WebPlotDigitizer

23. Akaike H. Likelihood of a model and information criteria. J Econom. 1981;16(1):3-14.

24. Uba G, Ginsau MA, Zandam ND, Shukor MY. Mathematical Modeling of the Effect of Adiantum philippense Extracts on Biofilms Formation, Adhesion with E. coli Activities Against Foodborne Pathogens. J Environ Microbiol Toxicol. 2020;8(2):611.

25. Sakamoto Y, Ishiguro M, Kitagawa G. Akaike information criterion statistics. Tokyo: Dordrecht; Boston: Hingham, MA: KTK Scientific Publishers; D. Reidel ; Sold and distributed in the U.S.A. and Canada by Kluwer Academic Publishers; 1986. 290 p. (Mathematics and its applications (Japanese series)).

26. Aisami A, Abubakar U, Manogaran M, Shukor MY. Test for the Presence of Autocorrelation in the Morgan-Mercer-Flodin (MMF) Model used for Modelling the Total Number of COVID-19 Cases for Brazil. Bull Environ Sci Sustain Manag E-ISSN 2716-5353. $2021 \mathrm{Jul}$ 31;5(1):32-6.

27. Mansur R, Gusmanizar N, Dahalan FA, Masdor NA, Ahmad SA, Shukor MS, et al. Isolation and characterization of a molybdenum- reducing and amide-degrading Burkholderia cepacia strain neni-11 in soils from west Sumatera, Indonesia. IIOAB. 2016;7(1):28-40.

28. Calvayrac C, Romdhane S, Barthelmebs L, Rocaboy E, Cooper JF, Bertrand C. Growth abilities and phenotype stability of a sulcotrione-degrading Pseudomonas sp. isolated from soil. Int Biodeterior Biodegrad. 2014;91:104-10.

29. Tang X, Jin M, Sun W, Xie J, Pan Y, Zhao Y. Comparison of growth parameters of pathogenic and nonpathogenic Vibrio parahaemolyticus on cooked shrimp. J Pure Appl Microbiol. 2013;7(SPL.ISSUE):47-51.

30. Zwietering MH, Jongenburger I, Rombouts FM, Van't Riet K. Modeling of the bacterial growth curve. Appl Environ Microbiol. 1990;56(6):1875-81.

31. Baranyi J, Roberts TA. Mathematics of predictive food microbiology. Int J Food Microbiol. 1995 Jul 1;26(2):199-218.

32. Ross T, McMeekin TA. Predictive microbiology. Int J Food Microbiol. 1994;23(3-4):241-64.

33. Peleg M, Cole MB. Reinterpretation of microbial survival curves. Crit Rev Food Sci Nutr. 1998;38(5):353-80.

34. Fang T, Gurtler JB, Huang L. Growth Kinetics and Model Comparison of Cronobacter sakazakii in Reconstituted Powdered Infant Formula. J Food Sci. 2012;77(9):E247-55.

35. Saratale GD, Saratale RG, Banu JR, Chang J-S. Biohydrogen Production From Renewable Biomass Resources. In: Biohydrogen [Internet]. Elsevier; 2019 [cited 2021 Oct 23]. p. 247-77. Available from:

https://linkinghub.elsevier.com/retrieve/pii/B97804446420350001 01

36. Vogel HC, Todaro CL, editors. Fermentation and biochemical engineering handbook: principles, process design, and equipment. Third edition. Amsterdam: William Andrew, an imprint of Elsvier; 2014. $434 \mathrm{p}$.

37. Smith J, Cremaschi S, Crunkleton D. CFD-Based Optimization of a Flooded Bed Bioreactor for Algae Production. In: Computer Aided Chemical Engineering [Internet]. Elsevier; 2012 [cited 2021 Oct 23]. p. 910-4. Available from: https://linkinghub.elsevier.com/retrieve/pii/B97804445950655001 34 